\title{
Research on the Risk Associated with Rural Drinking Water Safety Based on Catastrophe Theory
}

\author{
Chao Wang ${ }^{1}$, Fu-Quan Ni ${ }^{* 1,2}$, Yu Deng ${ }^{2}$, Lin-Lin Jiang ${ }^{3}$ \\ ${ }^{1}$ College of Information and Engineering, Sichuan Agricultural University, Ya'an, China \\ ${ }^{2}$ Provincial Key Laboratory of Agricultural Environmental Engineering, Sichuan Agricultural University, Ya'an, China \\ ${ }^{3}$ College of Civil Engineering, Tianjin University, Tianjin, China \\ E-mail:nfq1965@163.com
}

Received March 25, 2011; revised April 28, 2011; accepted June 1, 2011

\begin{abstract}
In this study, based on the analysis of the catastrophic risk of rural drinking water, with the representative villages in Ya'an as study objects and setting the four evaluation standards: water quality, water quantity, the Guarantee Probability for water Supply and the Convenience Level of the Access to Water Supply as the basic framework, a Rural Drinking Water Safety Assessment was developed (RDWSA). Research showed that Catastrophe Theory was applicable in the RDWSA. Adding RDWSA based on Catastrophe Theory to the supportive system for decision-making in Ecological Hydrographic Management Decision Support System of Ya'an helped obtain the rank and results of RDWSE by the automatic calculation of programs, which could assist the risk assessment and risk management associated with rural drinking water in Ya'an.
\end{abstract}

Keywords: Catastrophe Theory, Risk, Rural Drinking Water Safety, Ya’an

\section{Introduction}

Water is one of the most important natural resources for human development. But with the development of the social economy, the discharge of industrial wastes and domestic pollutants has worsened the water environment. Less water remains suitable for human consumption. More and more countries and relevant organizations have paid growing attention to drinking water issues, especially drinking water safety (DWS). Ensuring the safety of drinking water has become a focus drawing attention of the whole world [1,2]. Over the past decades, the Chinese government has made significant efforts in expanding supply of safe drinking water in rural areas. However, over 300 million rural residents still have no access to safe drinking water, facing problems of shortge as well as the increasing contamination and subsequent health threats [3]. Acceptable levels for DWS are set so that drinking water risk that is low enough to be ignored. Drinking such water will not lead to severe disease or an increased risk of death [4].

In 2004, China Ministry of Water Resources and Ministry of Health published the rural drinking water safety and health assessment index system which composed by four indicators including water quality (WQL), water quantity (WQT), Convenience, and Guaranteed Rate, thereby judging the safety of drinking water [5]. Rural DWS is not only closely bound up with the residents' production activity and the domestic life but also plays a key role in the state economic development, the stability and sustainable development of the society. In the past, methods of subjectively determine the weight of the indexes including Entropy Weight [6] Analysis of Hierarchy Process (AHP) [7] were mainly applied. Compared with the previous assessment methods, Catastrophe Theory does not determine the index weight and reduce the subjective factor, and the calculation is simple and convenient. Catastrophe Theory is a well-established approach with applications in different research areas such as physics [8], building [9], environment [10], as well as be applied in business [11].

In this study, based on Catastrophe Theory, a hierarchical structure evaluation indexes system was derived. And with the aid of VB program language, Rural Drinking Water Safety Assessment was developed (RDWSA) based on Catastrophe Theory was inserted into the supportive system for decision-making in ecological hydrographic risk management and the evaluation of the DWS of resources in rural Ya'an was performed. In this way, the method of determining the values by weight, which is 
obviously subjective, is avoided, and the results are more scientific and reasonable.

\section{Materials and Method}

\subsection{Overview of the Studied Area}

Located on the western edge of the Sichuan basin, Ya'an lies between longitudes $101^{\circ} 56^{\prime}$ and $103^{\circ} 20^{\prime} \mathrm{E}$, and latitudes $28^{\circ} 51^{\prime}$ and $30^{\circ} 56^{\prime} \mathrm{N}$, joining the Sichuan basin and the Tibetan plateau. Besides Yucheng city zone, there are another seven counties in Ya'an including Mingshan county, Yingjing county, Hanyuan county, Shimian county, Tianquan county, Lushan county and Baoxing county. The ground features of Ya'an are quite complicated for the criss-crossing mountains and the sharply cut landform. Ya'an has a very rich water reserve, with a to- tal amount of $3.6 \times 1010 \mathrm{~m} 3$. The per capita water possession there is 4.6 times that national average and 3.9 times that provincial average [12]. Ya'an enjoys excep- tional advantage in exploiting water resources. However the present state of the rural DWS is unfavorable. Ac- cording to statistics, 580,200 residents distributed in 383 villages have a difficult access to drinking water or drink insanitary water, amounting to $46.8 \%$ of the agricultural population. The main problems of the rural DWS are embodied in the following aspects: first, some water resources are with high fluoride content causing high morbidity rate of water-borne Skeletal Fluorosis, KaschinBeck disease and dental fluorosis, etc.; second, some towns in Lushan county and Tianquan county are known as heavy bilharzias-affected areas whose untreated water is severely schistosome-polluted; third, the ground water in Mingshan county and Yucheng city zone has high mirabilite content, which is undrinkable; fourth, it is extremely inconvenient to access drinking water for those who live in the terrain of medium and high mountains due to the widely spread population and the lack of transportation infrastructure and water resource facilities; fifth, some residents in the Yucheng city zone drink directly those untreated water from streams, reservoirs, pools and rivers; sixth, a heavy rain area though Ya'an is, seasonally water shortage and low GPWS in places where well water and stream water are main water resources remain a serious problem due to the uneven precipitation and less rainfall in winter and spring[5].

\subsection{WQL Index}

In 2005, the method of random sampling was adopted in the procedure of collecting data, based on the survey of the fundamental state and the recent general investigation on the rural drinking water (RDW) by the Health Ministry, considering comprehensively the studied area's to- pography, hydrography, water system, water resources, the distribution of diseases linked with drinking water and the types of water supply projects. Source water of central water supply, peripheral water, well water, reservoir water, water from waterworks and water resources often used by residents were set as sampling sites totaling 221 (Figure 1), and they were tested twice a month. The physical, chemical, toxicological, bacteriological and microbiological parameters were detected, amounting to twenty-one factors including color, turbidity, odor, macroscopic items, $\mathrm{pH}, \mathrm{COD}$, total hardness, total dissolved solid, chloride, sulphate, Fe, Mn , fluoride, As, $\mathrm{Hg}, \mathrm{Cd}, \mathrm{Cr}, \mathrm{Pb}$, nitrate, total coliforms and total bacteria count. This study selected water resources in eight representative villages as key studying objectives in this evaluation of the rural DWS based on TC, as shown in Table 1.

\subsection{Catastrophe Theory}

Catastrophe Theory, which originated with the work Structural Stability and Morphogenesis of the French mathematician René Thom in 1972 [13], is a mathematical theory studying non-continuous phenomena based on Topology and Structural stability theory. It explains the sudden changes of the behavior of a system in nature and

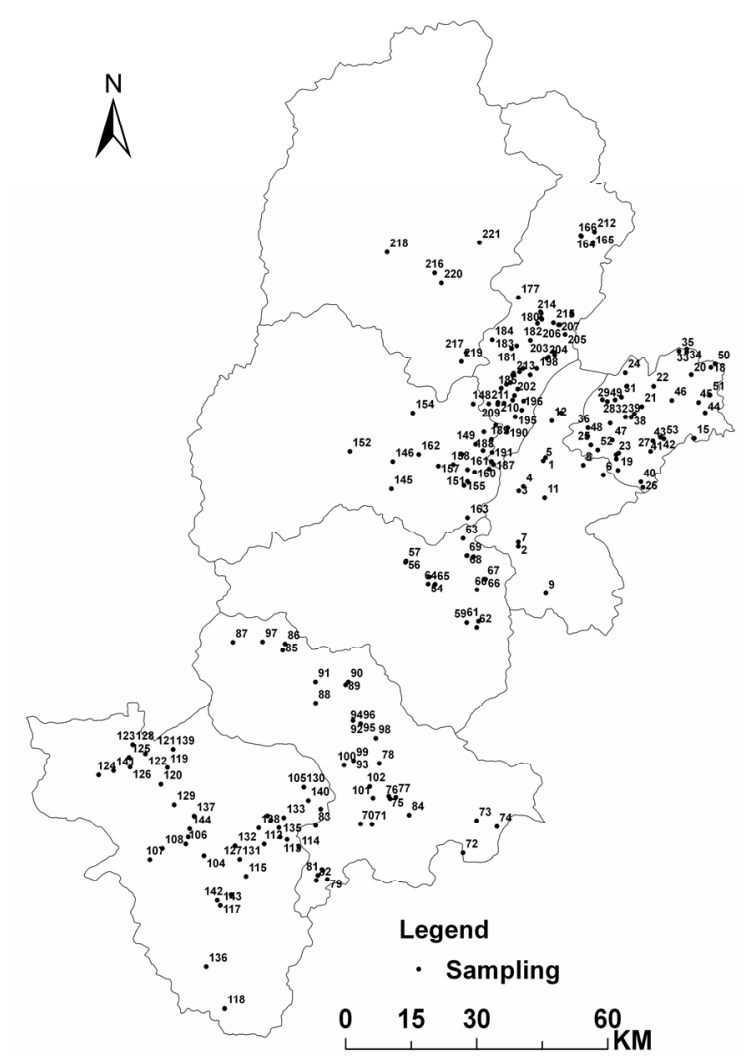

Figure 1. The distribution of sampling sites. 
Table 1 The initial data of special samples

\begin{tabular}{|c|c|c|c|c|c|c|c|c|c|c|c|}
\hline $\begin{array}{c}1 \mathrm{PP}^{\mathrm{st}} \mathrm{PP} \\
\text { layer }\end{array}$ & $\begin{array}{c}2 \mathrm{PP}^{\text {nd }} \mathrm{PP} \\
\text { layer }\end{array}$ & $\begin{array}{c}3 \mathrm{PP}^{\mathrm{rd}} \mathrm{PP} \\
\text { layer }\end{array}$ & $4 \mathrm{PP}^{\text {th }} \mathrm{PP}$ layer & $\begin{array}{c}\text { Liba village, } \\
\text { Yucheng } \\
\text { city }\end{array}$ & $\begin{array}{l}\text { Baizhang } \\
\text { reservoir, } \\
\text { mingshan } \\
\text { County }\end{array}$ & $\begin{array}{l}\text { Wannian } \\
\text { Village, } \\
\text { Yingjing } \\
\text { County }\end{array}$ & $\begin{array}{c}\text { Dashu water } \\
\text { factory, } \\
\text { Hanyuan } \\
\text { county }\end{array}$ & $\begin{array}{c}\text { Zaiyang } \\
\text { water } \\
\text { supply } \\
\text { station, } \\
\text { Shimian } \\
\text { county }\end{array}$ & $\begin{array}{l}\text { Xiaohe } \\
\text { Qiufeng } \\
\text { Village, } \\
\text { Tianquan } \\
\text { County }\end{array}$ & $\begin{array}{l}\text { Taiping } \\
\text { river, } \\
\text { Lushan } \\
\text { county }\end{array}$ & $\begin{array}{c}\text { Dayu } \\
\text { village, } \\
\text { Baoxing } \\
\text { county }\end{array}$ \\
\hline \multirow{22}{*}{ A1 } & \multirow{10}{*}{ B1 } & \multirow{3}{*}{ C1 } & $\mathrm{D}(\mathrm{mg} / \mathrm{L}$ & 174 & 0 & 100 & 0 & 97 & 435 & 200 & 0 \\
\hline & & & D2 & 176.2 & 102 & 70 & 166 & 80 & 230 & 168 & 114 \\
\hline & & & D3(mg/L) & 2 & 1.4 & 1.95 & 1 & 1.4 & 0 & 0.8 & 0 \\
\hline & & \multirow{3}{*}{$\mathrm{C} 2$} & D4 & 8.57 & 8.1 & 7.37 & 8.2 & 7.33 & 7.2 & 7.55 & 7.9 \\
\hline & & & D5 (mg/L) & 0.2 & 0.08 & 0.04 & 0 & 0.2 & 0.2 & 0.05 & 0.04 \\
\hline & & & D6 (mg/L) & 0.1 & 0.05 & 0.04 & 0 & 0.05 & 0.05 & 0.04 & 0.04 \\
\hline & & \multirow{2}{*}{ C3 } & D7 (mg/L) & 0 & 1.92 & 5 & 11.2 & 4.7 & 10.5 & 3 & 4.1 \\
\hline & & & D8 (mg/L) & 22.8 & 18 & 6.23 & 40 & 10 & 120 & 22 & 37.5 \\
\hline & & \multirow{2}{*}{ C4 } & D9 & 5 & 5 & 8 & 0 & 4 & 4 & 4 & 4 \\
\hline & & & D10 & 3 & 2 & 3 & 1 & 1 & 0.5 & 3 & 2 \\
\hline & \multirow{7}{*}{ B2 } & \multirow{3}{*}{$\mathrm{CRR}_{5}$} & D11 (mg/L) & 0.12 & 0.2 & 0.015 & 0.1 & 0.2 & 0.8 & 0.2 & 0.08 \\
\hline & & & D12 (mg/L) & 0.1 & 0.1 & 0.72 & 0 & 5.2 & 1.9 & 4 & 0 \\
\hline & & & D13 (mg/L) & 0.004 & 0 & 0.008 & 0 & 0.04 & 0.04 & 0.015 & 0.015 \\
\hline & & \multirow{4}{*}{ C6 } & D14 (mg/L) & 0.01 & 0 & 0.008 & 0 & 0.04 & 0.008 & 0.008 & 0.008 \\
\hline & & & D15 (mg/L) & 0.006 & 0 & 0.045 & 0 & 0.045 & 0.045 & 0.008 & 0 \\
\hline & & & D16 (mg/L) & 0.005 & 0 & 0 & 0 & 0.008 & 0.004 & 0.008 & 0 \\
\hline & & & D17 (mg/L) & 0.001 & 0 & 0 & 0 & 0.0008 & 0.0008 & 0.0008 & 0 \\
\hline & \multirow{5}{*}{ B3 } & & D18(CFU/mL) & 260 & 100 & 203 & 2 & 34 & 100 & 40 & 210 \\
\hline & & & D19(CFU/mL) & 230 & 3 & 360 & 0 & 2 & 235 & 10 & 110 \\
\hline & & A2 & & 0.728 & 1 & 0.962 & 0.972 & 0.498 & 1 & 1 & 0.985 \\
\hline & & A3 & & 0.868 & 0.878 & 1 & 1 & 1 & 1 & 1 & 0.940 \\
\hline & & A4 & & 0.965 & 0.950 & 1 & 0.979 & 1 & 1 & 1 & 0.923 \\
\hline
\end{tabular}

Table 2 catastrophe theory model

\begin{tabular}{|c|c|c|c|}
\hline Contents & Cusp catastrophe & Swallowtail catastrophe & Butterfly catastrophe \\
\hline Potential function f(x) & $1 / 4 \mathrm{XPP}{ }^{4} \mathrm{PP}+1 / 2 \mathrm{aXPP}{ }^{2} \mathrm{PP}+\mathrm{bX}$ & $1 / 5 X P P^{5} \mathrm{PP}+1 / 3 a X P P^{3} \mathrm{PP}+1 / 2 b X P P^{2} \mathrm{PP}+\mathrm{cx}$ & $\begin{array}{c}1 / 6 \mathrm{XPP}{ }^{6} \mathrm{PP}+1 / 4 \mathrm{aXPP}{ }^{4} \mathrm{PP}+1 / 2 \mathrm{bXPP}{ }^{3} \mathrm{PP} \\
+1 / 2 \mathrm{CXPP} P \mathrm{PP}+\mathrm{dx}\end{array}$ \\
\hline Bifurcation equation & $A=-6 x P P^{2} P P, b=8 x P P^{3}$ & 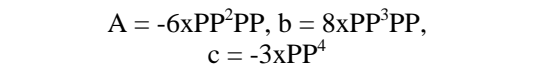 & 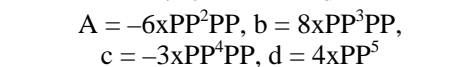 \\
\hline Normalizing formula & $\mathrm{Xa}=\mathrm{aPP} \mathrm{P}^{1 / 2} \mathrm{PP}, \mathrm{Xb}=\mathrm{bPP}^{1 / 3}$ & $\begin{array}{c}\mathrm{Xa}=\mathrm{aPP}^{1 / 2} \mathrm{PP}, \mathrm{Xb}=\mathrm{bPP}^{1 / 3} \mathrm{PP} \\
\mathrm{Xc}=\mathrm{cPP}^{1 / 4}\end{array}$ & $\begin{array}{c}\mathrm{Xa}=\mathrm{aPP}^{1 / 2} \mathrm{PP}, \mathrm{Xb}=\mathrm{bPP}^{1 / 3} \mathrm{PP}, \\
\mathrm{Xc}=\mathrm{cPP}^{1 / 4} \mathrm{PP}, \mathrm{Xd}=\mathrm{dPP}^{1 / 5}\end{array}$ \\
\hline Controlled variables & 2 & 3 & 4 \\
\hline
\end{tabular}

society by a series of mathematical models and describes the phenomena where the stability is lost and the system will make a sudden transition to a new, very different behavior $[9,14]$. It is characterized by classifying the critical points of the potential function to study the features of the instability in the space round them. Cusp catastrophe, Swallowtail catastrophe and Butterfly catastrophe are most commonly used for comprehensive evaluation $[10,15]$. As shown in Table 2, $f(x)$ is the state variable's potential function of the system and the coefficients of $X, a, b, c$ and $d$ are controlled variables of the state variable.

The potential function, $f(x)$, assembles all the critical points into a profile of equilibrium. By derivation, the bifurcation equation can be obtained. The bifurcation equation indicates that when controlled variables satisfy it, the system will suddenly transit into a new, very different behavior.

\subsection{Method for Rural DWS Assessment}

1) The establishment of the indexes of the comprehendsive evaluation of rural DWS

In this study, based on the intensive study of the features of one city zone and seven counties of Ya'an involved in DWS, referring to multiple theses that employed TC in studying water resources and combined with the data obtained in the experiment, the four stan- 
dards: WQL, WQT, Convenience, and Guaranteed Rate, were set as the basic framework. Evaluation of drinking WQL is an important item in the evaluation of rural DWS. As an exploratory experiment, this study referred to the Sanitary Standard for Drinking Water (GB 5749-2006), established an index system with WQL as its mainstay and performed evaluation of rural DWS.

2) The standardization of indexes

Membership degree function value was adopted for the calculation of the four indexes: forward formula was employed to calculate the WQL index and the formula is $x_{i j}=y_{i j} / \max \left(y_{i j}\right)$ : inverse formula was used to calculate WQT index, Convenience, and Guaranteed Rate, and the formula is $x_{i j}=\min \left(y_{i j}\right) / y_{i j} . I=A, B, C, D ; j=1,2 \cdots, m$ (m refers to the numbers of indexes), therefore ensures the final evaluation value tending to be on the small side. Convert the original data in the bottom level into catastrophic fuzzy membership function value within $[0,1]$.

3) The normalization calculation

Based on the numbers of the indexes, the catastrophe model to which the controlled variables correspond was employed. Applying the normalizing formula to do comprehensive quantitative recursion calculation and obtain the total catastrophic membership function value. When applying the normalizing formula to calculate the corresponding value, $X$, of each controlled variable of the same object, the minimum value or the average value was taken: given that those controlled variables aren't substitutable, i.e. they can't complement each other and are in non-complementary relation, the minimum value will be taken to obtain the total catastrophic membership function value; on the contrary, if they are in complementary relation, the average value will be taken to obtain the total catastrophic membership function value. Based on the analysis of the result, the comprehensive evaluation value varies within $[0,1]$, the larger the value is, the less safe the rural drinking water is.

\section{Results and Analysis}

\subsection{Computation}

According to the steps of the TC-based evaluation in Table 1, the normalization formula was applied to the comprehensive calculation of the indexes system established in Figure 2, from the lowest layer upward, until the catastrophe progression of the highest layer is got. Take the Liba Village in Yucheng City zone as example and the calculation procedure as follows:

Step 1, Normalization

$$
\begin{gathered}
X_{D 1}=y_{i j} / \max \left(y_{i j}\right)=174 / 435=0.4 \\
X_{D 2}=176.2 / 230=0.766
\end{gathered}
$$

$$
X_{D 3}=2 / 2=1
$$

Step 2, Catastrophe calculation

As shown in Table 2, D1, D2 and D3 in the bottom layer, which construct a Swallowtail catastrophe, using the corresponding equation: $X_{D 1}=(0.4) 1 / 2=0.6324, X_{D 2}$ $=(0.766) 1 / 3=0.9149, X_{D 3}=(1) 1 / 4=1$. In this equation, $D 1, D 2$ and $D 3$ complement each other, acting together on the upper assessment indicators. Therefore, according to the principles of mean value, $C 1=\left(X_{D 1}+X_{D 2}+X_{D 3}\right)$ $/ 3=0.8492$. Where, D4, D5 and D6 construct a Swallowtail catastrophe and $C 2=1$. In this equation, $C 3, C 4$ constitute the cusp catastrophe and Butterfly catastrophe respectively, $C 3=0.2874$ and $C 4=0.4476$. In addition, according to the principles of mean value, $B 1$ is equal to 0.8763 . Using the same method, $B 2$ is equal to 0.6393 and $B 3$ is equal to 0.9307 , and so $A 1, A 2, A 3$, and $A 4$ are equal to $0.9266,0.6841,1$ and 0.9567 respectively. The total catastrophe fuzzy membership function, $A$, is equal to 0.9587 .

\subsection{Analysis}

With the support of the supportive system for the decision-making in ecological hydrographic risk management of Ya'an and applying VB program language, RDWSA based on Catastrophe Theory to was added to the system module.

This submodule was employed in the evaluation of the water safety of 221 water resources. This study will present in detail the evaluation results of drinking water safety in eight representative villages. Results were ranked and their catastrophic risk values are shown in Figure 3.

The catastrophic risk value 0.8762 of Dashu water factory in Hanyuan County ranks top indicating the rural DWS here is at the lowest risk among the eight representative villages. Hanyuan County is a mountainous area having complex and varied terrains and landforms. It is topographically high in the northwest and low in the southeast with deep mountainous river downcuts and huge longitudinal slopes. Influenced by Qionglai Mountain Ridge and river, the precipitation is uneven and the river valley is relatively dry and hot with an annual precipitation of $730.8 \mathrm{~mm}$ and an annual flowthrough of 731.3 $\mathrm{mm}$, lower than the average level of Ya'an. The drinking water is with low heavy metal content while the fluoride content is quite high causing high morbidity rate of water-borne Skeletal Fluorosis, Kaschin-Beck disease and dental fluorosis.

The catastrophic risk value 0.9107 of Baizhang reservoir water in Mingshan County ranks second showing the rural DWS is at a relatively low risk level. Located on the western edge of the Sichuan basin, Mingshan 


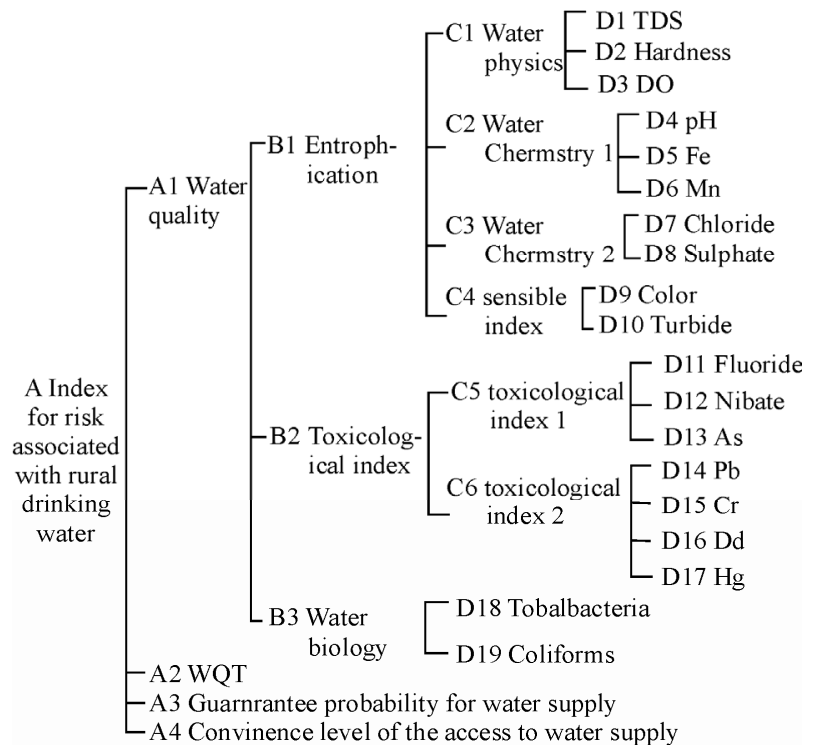

Figure 2 The index for risk associated with rural drinking water.

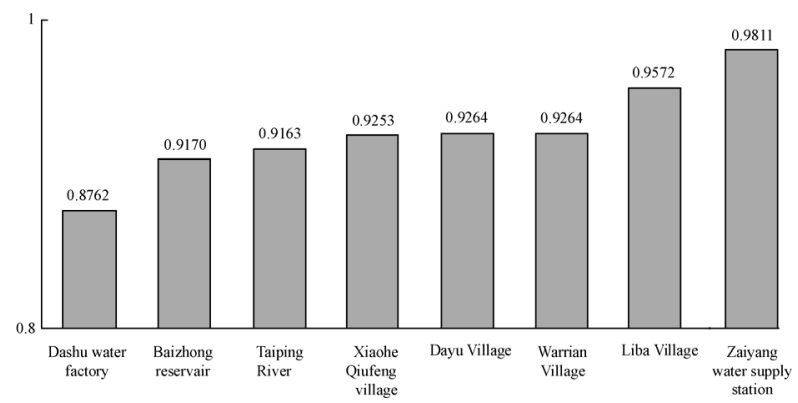

Figure 3. The catastrophe graphe of the case calculation.

landform is a syncline trough between the anticline of Mengshan Mountain and Zonggang Mountain, high in the northwest and low in the southeast. It consists mainly of hills and hummocks and Mingjiang River and the upstream of Qingyi River run through the terrain. Having a humid subtropical monsoon climate, the county is abundant in rainfall, with an annual precipitation of 1501.5 $\mathrm{mm}$.

Waters that permeate through the quaternary loose sand gravel and the fractures in bedrock are the main type of groundwater in the studied area. All the WQL indexes are within the safety range required. Some areas within Mingshan County are with high iron and manganese content because the background value of iron and manganese in groundwater underneath different soil material and soil type varies significantly [16]. Rural residents are widely spread, the economic development lags relatively behind and the infrastructure facility is weak, therefore, groundwater remains the main drinking water resource for domestic use. That as much as $86 \%$ of the residents rely mainly on groundwater reduces the safety guarantee of drinking water in Mingshan County.

The catastrophic risk value 0.9163 of Taiping Great River in Lushan County ranks third, indicating the rural DWS is at medium or low risk. Lushan County has an annual precipitation as much as of $1313.1 \mathrm{~mm}$, thus the rural residents here have a high Guaranteed Rate. And the $\mathrm{PH}$ value of the water is 7.55 , very close to that of neutral water. However the County is a heavy bilharzias-affected area and its untreated water is severely schistosome-polluted.

The catastrophic risk value 0.9253 of Qiufeng group three, Xiaohe village in Tianquan County ranks fourth indicating the rural DWS is at medium risk. The landform is medium-deeply cut or deeply cut, high in the northwest and low in the southeast. Tianquan County is abundant in rainfall with an annual precipitation of $1660 \mathrm{~mm}$. It rains at an extremely high frequency of $73 \%$, over $200 \mathrm{~d} / \mathrm{a}$. The average annual surface runoff volume within the terrain in years is 3.771 billion $\mathrm{m}^{3}$. The county has a forest coverage amounting to $50.23 \%$, a total water resource of 6.714 billion $\mathrm{m}^{3}$ and a per capita water possession of $2,724 \mathrm{~m}^{3}$. The soil type here mainly comprises purple soil, yellow soil and yellow-brown soil, close to acid soil. The water is with high Calcium carbonate concentration resulting in high hardness which is almost 3.5 times that in Yingjing County, and it is with the highest content of dissolved solid and sulphate, causing high morbidity of gallstone.

The catastrophic risk value 0.9264 of Dayu Village, Lingguan Town in Baoxing County ranks fifth indicating the rural DWS is at medium or high risk. Mountains cover $99.7 \%$ of the area and with an annual precipitation of $953 \mathrm{~mm}$, water shortage is likely to happen. Folds are highly concentrated within the terrain, the fracture development and construction impacts significantly on the topography and the soil material varies. Dissolved solids were absent and toxicological indexes were low in detection while the total bacteria are $210 \mathrm{CFU} / \mathrm{mL}, 2.1$ times of the limit set by the Sanitary Standard for Drinking Water.

The catastrophic risk value 0.9264 of Wannian Village, Shizi Town in Yingjing County ranks sixth indicating the rural DWS is at high risk with low safety level. It is abundant in rainfall. The precipitation is uneven and flooding remains serious in those mountainous areas. The county has rich water resources with an annual average volume of 3.483 billion $\mathrm{m}^{3}$, and the runoff is 1702 $\mathrm{mm}$ deep and the flow coefficient is 0.86 . E. coli is 360 MPN/100mL L, significantly exceeding the standard.

The catastrophic risk value 0.9572 of Liba Village, Yucheng city zone ranks seventh indicating the rural DWS is at a relatively high risk. Located in the central region of the Qingyi river Valley, Yucheng city zone is a 
broad area high in the west and low in the east. It is topographically an intermountain basin and a valley terrace of low and medium mountains. The city zone is abundant in orographic rainfall with an annual average precipitation of $1732 \mathrm{~mm}$ and annual rainy days of 218. As a relatively densely inhabited district and impacted by human activities, industrial wastewater and domestic wastewater, the amount of direct drinking water is insufficient causing drinking water shortage.

In this case, the catastrophic risk value of Liba Village is 0.9587 by hand calculation while it is 0.9572 when calculated by program. The 0.0015 difference results from rounding errors: the four digits after the decimal point were kept as valid figure in the hand calculation while in the program calculation the figures of far more than four digits were kept as valid figures, therefore, 0.0015 is a permissible error.

The catastrophic risk value 0.9811 of the water supply station in Zaiyang town, Shimian County ranks eighth indicating the rural DWS here is at the highest risk among all the sampling sites. The exploitable water resources in Shimian County are quite rich while the precipitation and water suitable for direct drinking are in insufficient. During the low flow period of winter and spring, the water reserve in those villages relying on well water and stream water are in severe shortage, causing seasonal water shortage and low GPWS. The residents drank those substandard untreated water from the streams, reservoirs, pools and rivers, thus, the drinking water safety is at quite low level.

Although evaluation methods based on Catastrophe Theory are unavoidably subjective to certain extent, similar to that of other mathematical methods, it is still widely applied in the field of natural science. The calculation is simpler and more precise, therefore, this method is highly recommended by studies.

Based on the regional condition of the rural drinking water, apply practicable structural measures to increase resources of favorable quality, design a rational layout of the rural drinking water projects distribution and make a scientific planning of the engineering construction, taking into consideration of different geographic features of the mountainous areas, bugori, plains and suburbs. And particular emphasis should be given to the distribution of the population, the need for water supply and the economic development.

\section{Conclusions}

The attempt of employing it in the risk evaluation of the rural drinking water safety has provided a new method in the risk evaluation of drinking water safety. In this study, the magnitude of the evaluation indexes was determined and quantified by the normalization formula referring to the relationship among the impacting factors, which is relatively scientific and practicable. In this way, the method of determining the values by weight, which is obviously subjective, is avoided. And the normalization formula is more applicable, easier realized by programs.

Substandard water quality is most tropical in the rural drinking water safety problems in Ya'an, among which water with high iron content, high manganese content and high fluoride content are the most common problems. Therefore, the key issue to ensure the rural DWS in Ya'an is to solve its specific water quality problems.

\section{Acknowledgements}

Education Reform Project Fundation of the Sichuan Education Department (Grant No. P09150), the National Innovative Project for College Students (Grant No. 00509204), the Youth Science and Technology Innovation Fund of Sichuan Agricultural University (Grant No. 00530300), the Talent Introduction Fund of Sichuan Agricultural University (Grant No. 00530301), and the Double-Support Plan of Sichuan Agricultural University (Grant No. 00570103).

\section{References}

[1] J. Bartram, J. Cotruvo, M. Exner, C. Fricker and A. Glasmacher, "Heterotrophic Plate Count Measurement in Drinking Water Safety Management," International Journal of Food Microbiology, Vol. 92, No. 3, 2004, pp. 241-247. doi:10.1016/j.ijfoodmicro.2003.08.005

[2] B. Ngwai, A. Sounyo, M. Fiabema, A. Agadah and O. Ibeakuzie, "Bacteriological Safety of Plastic-Bagged Sachet Drinking Water Sold in Amassoma, Nigeria," Asian Pacific Journal of Tropical Medicine, Vol. 3, No. 7, 2010, pp. 555-559. doi:10.1016/S1995-7645(10)60134-4

[3] "Improved Water Resources Management and Drinking Water Safety in Rural China,”

http://www.undp.org.cn/projects/56957.pdf.

[4] E. Hrudey, J. Hrudey and J. T. Pollard, "Risk Management for Assuring Safe Drinking Water,” Environment International, Vol. 32, No. 8, 2006, pp. 948-957. doi:10.1016/j.envint.2006.06.004

[5] F. Q. Ni, Y. L. Yang and H. Z. Ren, "The Study on the Assembled Gis-Based Supportive For the Rural Drinking Water Safety Decision-Making System,” The 5th China Water Forum: Environment Variation and the Water Safety, Zhenzhou, 2007, pp. 221-224.

[6] C. F. Yuan , H. J. Lei , H. W. Wang , H. W. Pan and J. X. $\mathrm{Xu}$, "Evaluation on Rural Drinking Water Safety of Henan Province,” Journal of Irrigation and Drainage, Vol 28, No. 6, 2009, pp. 59-63.

[7] B. H. Li, B. Y. Zhang and H. F. Qiao, "Study on Safety Index Evaluation for Rural Drinking Water in Jianghan 
Plain,” Journal of Yangtze University (Natural Science Edition), Vol. 5, No. 2, 2008, pp. 67-70.

[8] D. J. Wales, "A Microscopic Basis for the Global Appearance of Energy Landscapes,” Science, Vol. 293, No. 5537, 2001, pp. 2067-2670.

[9] K. T. W. Yiu and S. O. Cheung, “A Dynamic Nonlinear Model of Online Retail Competition Using Cusp Catastrophe Theory," Building and Environment," Vol. 41, No. 4, 2006, pp. 438-447. doi:10.1016/j.buildenv.2005.01.007

[10] J. T. Liu, J. F. Gao, J. H. jiang, J. C. Huang and J. H. Zhao, "Castrophe Theory-Based Risk Evaluation of Blue Green Algae Bloom in Different Regions of Lake Taihu,” Journal of Lake Science, Vol. 22, No. 4, 2010, pp. 488-494.

[11] W. Dou and S. Ghose, “A Dynamic Nonlinear Model of Online Retail Competition Using Cusp Catastrophe Theory,” Journal of Business Research, Vol. 59, No. 7, 2006, pp. 838-848. doi:10.1016/j.jbusres.2006.02.003
[12] M. X. Liu, “The Water Resources Management and Its Countermeasures,” Chengdu water conservancy, 2003, pp.18-19.

[13] R. Thom, "Structural Stability and Morphogenesis,” Addison Wesley, Boston, 1975.

[14] W. J. Wang, S. L. Liu, S. S. Zhang and J. W. Chen, “Assessment of a Model of Pollution Disaster in Near-Shore Coastal Waters Based on Catastrophe Theory,” Ecological Modelling, Vol. 59, 2010, pp.1-6.

[15] A. Kuijper and M. J. Florack, "Using Catastrophe Theory to Derive Trees from Images," Kluwer Academic Publishers, Netherlands, 2004, pp. 1-32. doi: 10.1007/s10851-005-0481-9

[16] Y. F. Hu, L. J. Deng, S. R. Zhang, F. Q. Ni, and J. Zhang, "Spatial Variability of Iron and Manganese Contents in Shallow Groundwater in the West of Sichuan Basin," Acta Ecologica Sinica, Vol. 29, No. 2, 2009, pp. 797-803. 